\title{
Membranoproliferative glomerulonephritis
}

\author{
Bassam Alchi • David Jayne
}

Received: 26 June 2009 /Revised: 21 August 2009/Accepted: 27 August 2009 /Published online: 12 November 2009

(C) IPNA 2009

\begin{abstract}
Membranoproliferative glomerulonephritis is an uncommon kidney disorder characterized by mesangial cell proliferation and structural changes in glomerular capillary walls. It can be subdivided into idiopathic and secondary forms, which are differentially diagnosed by a review of clinical features, laboratory data, and renal histopathology. Three types-I, II, and III- have been defined by pathologic features. All three types are associated with hypocomplementemia, but they manifest somewhat different mechanisms of complement activation. Type II, also known as "dense deposit disease", is associated with the presence of C3-nephritic factor. Membranoproliferative glomerulonephritis primarily affects children and young adults, with patients presenting with nephrotic or nephritic syndrome or with asymptomatic renal disease. This type of glomerulonephritis often progresses slowly to end-stage renal disease, and it tends to recur after renal transplantation, especially type II. The efficacy of various forms of treatment remains controversial; however, long-term steroid treatment seems to be effective in children with nephrotic-range proteinuria. Improvement in renal outcomes largely relies on the evaluation of more selective agents in carefully controlled studies.
\end{abstract}

Keywords Cryoglobulinemia - Dense deposit disease . Hypocomplementemia mesangiocapillary $\cdot$ Nephritic factor

B. Alchi $\cdot$ D. Jayne $(\bowtie)$

Renal Unit, Addenbrooke's Hospital,

Box 118, Hills road,

Cambridge CB2 0QQ, UK

e-mail: dj106@cam.ac.uk

\section{Introduction}

The term membranoproliferative glomerulonephritis (MPGN) is often employed to denote a general pattern of glomerular injury seen in a variety of disease processes that share a common pathogenetic mechanism, rather than to describe a single disease entity [1]. It encompasses forms of unknown cause (idiopathic) and forms associated with systemic and infectious disorders (Table 1). Mixed essential cryoglobulinemia associated with chronic hepatitis $\mathrm{C}$ virus (HCV) infection has now been implicated in a substantial number of cases of what were previously thought to be idiopathic MPGN [2].

Morphologically, MPGN is characterized by diffuse mesangial cell proliferation and the thickening of capillary walls due to subendothelial extension of the mesangium; hence, the alternative term "mesangiocapillary glomerulonephritis". There are at least two (possibly three) distinct morphologic types of MPGN, and all three are related to complement activation (Fig. 1). Type I (classical MPGN), the most common variant, is characterized by the presence of subendothelial deposits of immune complexes associated with activation of the classical complement pathway. Type II MPGN (dense deposit disease), is a unique variant characterized by the presence of additional intra-membranous dense deposits. This type is known to be associated with a serum immunoglobulin, $\mathrm{C} 3$ nephritic factor $(\mathrm{C} 3 \mathrm{NeF})$, that stabilizes $\mathrm{C} 3$ convertase $(\mathrm{C} 3 \mathrm{bBb})$, thereby resulting in persistent activation of the alternative complement pathway. Type III MPGN, which some pathologists consider as a morphologic variant of type I, is characterized by the presence of additional subepithelial deposits.

Idiopathic MPGN is one of the least common types of glomerulonephritis, accounting for approximately 4 and $7 \%$ of primary renal causes of nephrotic syndrome in children 
Table 1 Classification of membranoproliferative glomerulonephritis

\begin{tabular}{|c|c|}
\hline Membranoproliferative glomerulonephritis & Associated with systemic and infectious disorders \\
\hline \multicolumn{2}{|l|}{ Idiopathic } \\
\hline \multicolumn{2}{|l|}{ Type I } \\
\hline \multicolumn{2}{|l|}{ Type II (dense deposit disease) } \\
\hline \multicolumn{2}{|l|}{ Type III } \\
\hline \multicolumn{2}{|l|}{ Secondary } \\
\hline \multirow[t]{4}{*}{ Infectious diseases } & Viral: Hepatitis B and C, human immunodeficiency virus \\
\hline & Bacterial: shunt nephritis, visceral abscesses, infective endocarditis \\
\hline & Protozoal: quartan malaria, schistosomiasis, leprosy \\
\hline & Other: mycoplasma, mycobacteria \\
\hline \multirow[t]{6}{*}{ Systemic immune complex diseases } & Mixed cryoglobulinemia \\
\hline & Systemic lupus erythematosus \\
\hline & Scleroderma \\
\hline & Sjögren's syndrome \\
\hline & Hereditary deficiencies of complement components \\
\hline & Hypocomplementemic urticarial vasculitis \\
\hline \multirow[t]{3}{*}{ Neoplasms } & Leukemias and lymphomas \\
\hline & Carcinomas \\
\hline & Light-chain disease and plasma cell dyscrasias \\
\hline \multirow[t]{2}{*}{ Chronic liver disease } & Chronic hepatitis \\
\hline & Cirrhosis \\
\hline \multirow[t]{8}{*}{ Miscellaneous } & Partial lipodystrophy \\
\hline & $\alpha 1$-Antitrypsin deficiency \\
\hline & Cystic fibrosis \\
\hline & Drugs (e.g. heroin, $\alpha$-interferon) \\
\hline & Sarcoidosis \\
\hline & Sickle cell disease \\
\hline & Hemolytic uremic syndrome \\
\hline & Transplant glomerulopathy \\
\hline
\end{tabular}

and adults, respectively [3]. The incidence of MPGN varies in different parts of the world, but has shown a decline in most developed countries. Interestingly, in Turkey and Nigeria, MPGN has been reported as the most common histopathologic subtype in children with nephrotic syn- drome who underwent renal biopsy [4, 5]. All types of MPGN typically have a slowly progressive clinical course. Nonetheless, only $2.8 \%$ of end-stage renal disease (ESRD) in children on dialysis and $3.3 \%$ of ESRD in pediatric renal transplant recipients are caused by MPGN [6].

Fig. 1 Schematic depiction of the complement system highlighting the different pathways of complement activation in the three types of membranoproliferative glomerulonephritis $(M P G N)$. NeFt Nephritic factor of the terminal pathway, $P$ properdin

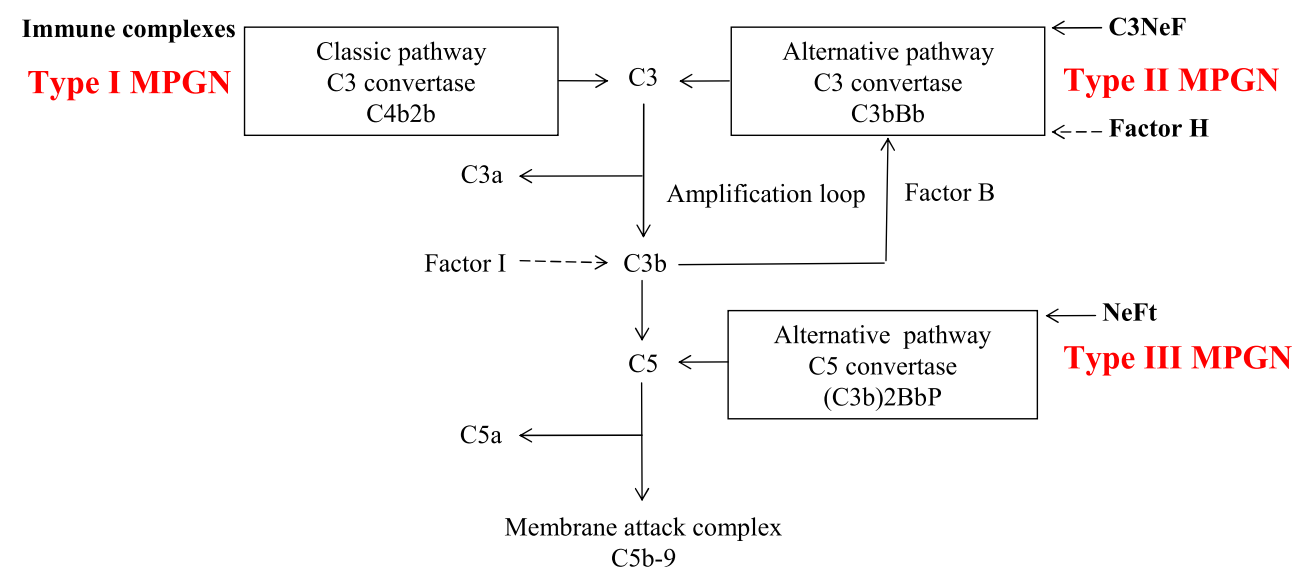




\section{Pathogenesis}

The pathogenesis of MPGN is not yet clearly understood. It is believed that type I MPGN results from chronic antigenemia and the generation of nephritogenic immune complexes that preferentially localize to the subendothelial spaces. The precise nature of the putative antigen(s) in most patients with type I MPGN is unknown; however, a specific pathogenic antigen can sometimes be demonstrated in the glomerular lesions [7]. Recent studies have demonstrated the contribution of innate immunity to both the generation of antibodies that are deposited as immune complexes and to the local inflammatory responses directed at the glomerular immune deposits $[8,9]$. The immune complexes activate the complement system via the classical pathway, leading to the generation of chemotactic factors $(\mathrm{C} 3 \mathrm{a}, \mathrm{C} 5 \mathrm{a})$ that mediate the accumulation of platelets and leukocytes and of terminal components (C5b-9) that directly induce cell injury. Leukocytes release oxidants and proteases that mediate capillary wall damage and cause proteinuria and a fall of glomerular filtration rate. Cytokines and growth factors released by both exogenous and endogenous glomerular cells lead to mesangial proliferation and matrix expansion [10].

The pathophysiologic basis for type II MPGN seems to be the uncontrolled systemic activation of the alternative pathway of the complement cascade [11, 12]. In most patients, loss of complement regulation is caused by the $\mathrm{C} 3$ nephritic factor $(\mathrm{C} 3 \mathrm{NeF})$, an immunoglobulin (Ig)G autoantibody that binds and prevents the inactivation of $\mathrm{C} 3$ convertase $(\mathrm{C} 3 \mathrm{bBb})$ of the alternative pathway, thereby resulting in the perpetual breakdown of $\mathrm{C} 3$. A further cause of type II MPGN is due to mutations in the complement regulatory protein, factor $\mathrm{H}$, or to autoantibodies that impede factor $\mathrm{H}$ function, highlighting the role of deregulated alternative complement pathway activity in type II MPGN [12].

Type II MPGN may occur in association with two other conditions, either separately or together: acquired partial lipodystrophy (APD) and macular degeneration. The abnormal activation of the alternative pathway of the complement system is the common link to these seemingly disparate diseases [13]. Acquired partial lipodystrophy is associated with the presence of circulating $\mathrm{C} 3 \mathrm{NeF}$, which can cause a complement-mediated lysis of adipocytes that in turn produce high concentrations of factor $\mathrm{D}$, also called adipsin. Factor D cleaves factor B, activating the alternative complement pathway. By analogy, $\mathrm{C} 3 \mathrm{NeF}$ may cause damage to glomerular cells that produce the complement. Nonetheless, $\mathrm{C} 3 \mathrm{NeF}$ can occur in apparently healthy individuals and in patients with other types of glomerular diseases. In addition, $\mathrm{C} 3 \mathrm{NeF}$ does not always correlate with the occurrence or progression of type II MPGN, suggesting the role of other factors [12].

Complement perturbation in type III MPGN is thought to be related to a slow-acting nephritic factor that stabilizes a properdin dependent $\mathrm{C} 5$-convertase, $(\mathrm{Cb} 3)$ $2 \mathrm{BbP}$, activating the terminal pathway; hence, the term nephritic factor of the terminal pathway (NeFt) [14]. This nephritic factor has not been reported in healthy subjects, unlike $\mathrm{C} 3 \mathrm{NeF}$. In addition, the deposits observed in renal biopsies of patients with type III MPGN are closely associated with the circulating nephritic factor-stabilized convertase and with hypocomplementemia, suggesting that $\mathrm{NeFt}$ is fundamental to the pathogenesis of type III MPGN [15].

The mechanism of renal injury in HCV-associated cryoglobulinemia remains elusive. An estimated 50-60\% of patients with chronic $\mathrm{HCV}$ infection develop type II cryoglobulins, which are composed of a complex of an IgM kappa monoclonal antibody with rheumatoid factor activity directed against a polyclonal anti-HCV IgG. However, only a minority (10-20\%) of such patients with detectible cryoglobulinemia have clinical manifestations of cryoglobulinemic MPGN [2]. It is unclear why some cryoglobulins are more pathogenic than others, or why cryoglobulins deposit in the kidneys. Recognition of the components of cryoprecipitates, which contain HCV core protein, by circulating leukocytes and intrinsic glomerular cells leads to the production of inflammatory mediators that characterize the glomerular injury of cryoglobulinemic MPGN.

\section{Clinical manifestations}

Membranoproliferative glomerulonephritis primarily affects children and young adults, with no sex predilection. In children, MPGN is frequently idiopathic, whereas in adults, MPGN is commonly associated with cryoglobulinemia and $\mathrm{HCV}$ infection. Patients with MPGN may present in one of four ways, as follows:

1. nephrotic syndrome (40-70\%);

2. acute nephritic syndrome (20-30\%);

3. asymptomatic proteinuria and hematuria detected on routine urinalysis $(20-30 \%)$;

4. recurrent episodes of gross hematuria (10-20\%).

A respiratory tract infection may precede the diagnosis in half of the patients. Hypertension is found at presentation in one third of patients but occurs more frequently with progressive disease. Renal dysfunction occurs in $>50 \%$ of patients. The incidence of anemia out of proportion to the degree of renal failure is common and is thought to be related to complement-mediated lysis of red blood cells. Compared with adults, children 
are more likely to have hematuria at onset and less likely to have renal insufficiency and hypertension [16].

The different types of MPGN cannot be distinguished based on clinical presentation. However, the presence of associated extra-renal manifestations, such as drusen or APD, suggests type II MPGN. In contrast to drusen that form in age-related macular degeneration, drusen in individuals with MPGN II occur at an early age and often are detectable in the second decade of life. Similarly, the loss of subcutaneous fat in the upper half of the body in APD usually precedes the onset of kidney disease by several years.

Hypocomplementemia is a characteristic feature of all types of MPGN, which is essentially the only cause of idiopathic nephrotic syndrome that is associated with hypocomplementemia. In type I MPGN and cryoglobulinemic MPGN, the classical pathway is preferentially activated (low or normal $\mathrm{C} 3$, low $\mathrm{C} 4$ and $\mathrm{CH}_{50}$ ), while in type II MPGN, the alternative pathway is activated (low C3, normal $\mathrm{C} 4$ and low $\mathrm{CH}_{50}$ ), and in type III MPGN, the complement profile typically reveals evidence of the activation of both the alternative and terminal pathways (low C3, normal C4 and low C5 through C9) [17]. The serological detection of nephritic factors is quite useful in distinguishing among the types of MPGN; however, apart from $\mathrm{C} 3 \mathrm{NeF}$, which is positive in over $80 \%$ of patients with type II MPGN and even more frequent in children, assays for other nephritic factors are performed primarily in research laboratories and are not widely available. The clinical and laboratory evaluation of patients with suspected MPGN is summarized in Table 2.

The natural history of MPGN is characterized by spontaneous fluctuations of the severity of the clinical picture, with very few cases of spontaneous, complete remission. Children tend to have a more acute presentation and a slower decline in renal function than adults. Approximately $40 \%$ of patients progress to ESRD within 10 years of diagnosis. Features suggestive of an adverse outcome include the nephrotic syndrome, renal dysfunction at onset, and persistent hypertension. Type II MPGN is associated with a worse prognosis, as is the presence of chronic interstitial damage on renal biopsy [18].

Membranoproliferative glomerulonephritis may recur in renal transplant recipients with a frequency of $20-30 \%$ for type I and $80-90 \%$ for type II. The North American Pediatric Renal Transplant Cooperative Study investigated the impact of type II MPGN recurrence in a large population of pediatric renal transplant patients [19]. The study indicated that recurrence had a significant negative impact on renal allograft function and survival, contributing to graft failure in $15 \%$ of recipients by 5 years posttransplantation. No clear predictors of disease recurrence were identified in the above-mentioned study.

\section{Histopathology}

\section{Type I MPGN}

The glomeruli often show a global increase in mesangial cellularity and matrix with diffuse endocapillary proliferation. Infiltrating mononuclear leukocytes and neutrophils also contribute to the glomerular hypercellularity. As a consequence of these changes, the glomerular tufts appear hyper-lobulated (Fig. 2b). Another distinctive feature of MPGN is the diffuse thickening and duplication of the glomerular basement membranes (GBM) that can be seen with Periodic acid-Schiff and silver stains. This appearance, also known as tram-tracking, splitting, or reduplication of the GBM, results from the presence of subendothelial deposits and the so-called "mesangial interposition" whereby mesangial cells, infiltrating mononuclear cells, or even portions of endothelial cells interpose themselves between the endothelium and basement membrane, with new, inner GBM-like material being laid down (Fig. 2b). Deposits can occasionally be demonstrated in the subendothelial location by trichrome staining. The proportion of cells to matrix varies with the duration of the disease. In advanced cases, lobular centers may become completely sclerosed, simulating the KimmelstielWilson nodules of diabetes. Glomerular crescents are present in approximately $10 \%$ of cases and may occur in both idiopathic and secondary forms [20]. The presence of eosinophilic hyaline globules in capillary lumina suggests mixed cryoglobulinemia and should be carefully sought. The interstitium, tubules, and vessels show nonspecific changes that correlate with the severity of chronic damage. Vasculitis affecting small and medium-sized renal arteries is strongly associated with underlying cryoglobulinemic MPGN [21].

The most common immunofluorescence finding is strongly positive staining for $\mathrm{C} 3$ and, less frequently, for IgG and IgM, in a fine to course granular pattern along the glomerular capillaries. This corresponds to the prominent subendothelial deposits seen by electron microscopy. Early complement components (C1q or $\mathrm{C} 4)$ and properdin are also frequently present. Occasionally the $\mathrm{C} 3$ deposits are predominantly mesangial.

Electron microscopy (Fig. 3a) reveals an expanded mesangium which contains cells, matrix, and often electron-dense deposits. The subendothelial space is widened and filled with mesangial cells and matrix continuous with those in the centrilobular mesangial area and with granular electron-dense deposits. The formation of a "new basement membrane" is demonstrated under the endothelial cell. There is an effacement of podocyte foot processes and occasional subepithelial small electrondense deposits. The detection of microtubular structures suggests cryoglobulinemia. 
Table 2 Evaluation of patients with suspected membranoproliferative glomerulonephritis $(M P G N)$

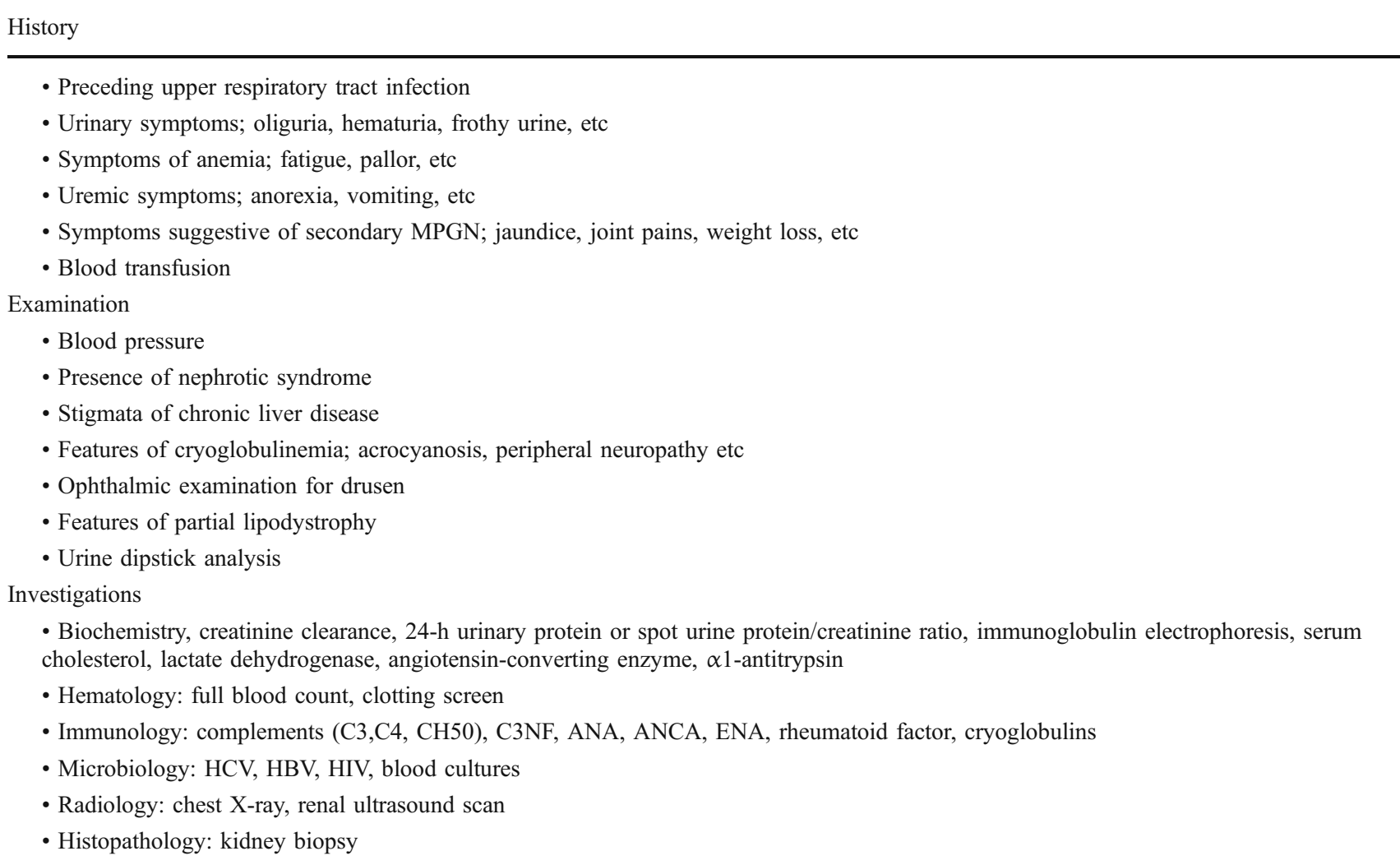

NF, Nephritic factor; ANA, antinuclear antibodies; ANCA, anti-neutrophil cytoplasmic antibodies; ENA, epithelial neutrophil-activating peptide; $\mathrm{HC}(\mathrm{B}) \mathrm{V}$, hepatitis virus $\mathrm{C}(\mathrm{B})$; HIV, human immunodeficiency virus

\section{Type II MPGN}

The glomerular changes in type II MPGN can be quite variable. Glomerular hypercellularity and lobulation, as in type I MPGN, is seen in only $25 \%$ of all cases [22]. Thus, the alternative term "dense deposit disease" is probably more accurate than the designation type II MPGN as the former emphasizes the pathognomonic feature of type II MPGN, which is the presence of elongated, brightly eosinophilic, variably refractile deposits within the GBM. The deposits may be continuous and ribbon-like or periodically interrupted, thereby having the appearance of a "string of sausages" (Fig. 2c). On silver-stained specimens, these intra-membranous deposits appear to be light brown and surrounded by darker lines forming a doublecontour. Similar deposits may be seen in the tubular basement membrane and Bowman's capsule. Crescents may be present.

Specimens studied by immunofluorescence microscopy show staining for $\mathrm{C} 3$, usually in a linear or granular pattern along the glomerular capillaries, and in the mesangium. Immunoglobulin is not detected, indicating that the dense deposits are not classic antigen-antibody immune complexes. However, segmental IgM or less often $\operatorname{IgG}$ and rarely IgA have been reported. Early complement components are usually absent.

The key feature observed on electron microscopy (Fig. 3b) is a layer of highly electron-dense material within the lamina densa of the glomerular capillary basement membrane that splits into two layers. Granular deposits of similar dense material are usually present in the mesangium. Similar deposits are also seen in some tubular basement membranes and Bowman's capsule.

\section{Type III MPGN}

This subtype of MPGN has some features in common with those seen in type I MPGN, such as double contours of the GBM and subendothelial deposits, together with widespread subepithelial deposits similar to those seen in membranous glomerulonephritis. However, hypercellularity is often less prominent than in type I MPGN [23]. Immunostaining reveals a heavy granular pattern along the glomerular capillary walls and mesangium for $\mathrm{C} 3$ and sometimes IgG and IgM. Ultrastructural studies may reveal multilayering of the basement membrane material and complex disruption of the lamina densa by large dense deposits. 

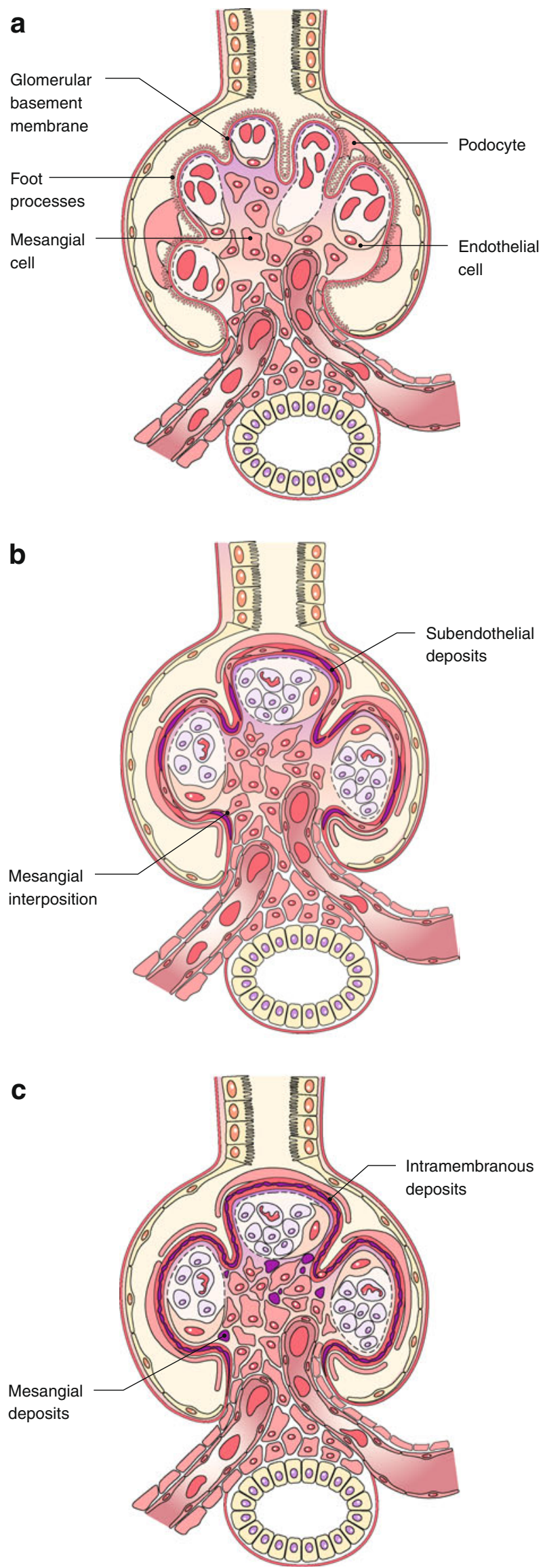

4 Fig. 2 In the normal glomerulus (a), the capillary loops are open, the mesangial areas have no more than three nuclei each, and the foot processes are intact, without any deposits or proliferation. In type I MPGN (b), the glomerulus appears to be lobulated due to extensive endocapillary proliferation, and the glomerular basement membrane has a split appearance as a result of the mesangial interposition and subendothelial deposits. In type 2 MPGN (c), the capillary walls appear to be thickened by dense deposits in a ribbon-like pattern, and the mesangial area also contains dense material

\section{Treatment}

The efficacy of the various therapeutic regimens tried in MPGN is difficult to assess because of the small patient numbers and short-term nature of published controlled trials; the larger trials carried out to date have been uncontrolled [24]. Moreover, most trials include patients with all three types of MPGN in different proportions, making the analysis of treatment results more difficult. Treatment strategies for idiopathic MPGN are controversial and have included corticosteroids, immunosuppressives, antiplatelet regimens, plasma exchange and biologic agents.

\section{Corticosteroids}

Both retrospective and prospective studies have demonstrated the beneficial effect of alternate-day steroid therapy on renal survival in pediatric patients with MPGN. Of these, a prospective, multicenter, randomized trial was conducted by the International Study of Kidney Disease in children (ISKDC) [25]. Eighty children, predominantly with type I MPGN were randomized to receive either $40 \mathrm{mg} / \mathrm{m}^{2}$ of prednisone every other day or placebo for a mean duration of treatment of 41 months. Criteria for admission included heavy proteinuria and a glomerular filtration rate $(\mathrm{GFR}) \geq 70 \mathrm{ml} / \mathrm{min} / 1.73 \mathrm{~m}^{2}$. Treatment failure (30\% increase in serum creatinine) occurred less frequently $(40 \%)$ in patients treated with prednisone than in those who received placebo $(55 \%)$, and $61 \%$ of the treatment group versus $12 \%$ of the placebo group had stable renal function at the end of the study. The use of such a protracted course of steroid medication is not without adverse effects, particularly on bone growth. Non-nephrotic children may forego steroid treatment without compromising long-term kidney function [26]. While corticosteroid therapy seems to be effective in children, there is no convincing published evidence that steroids are effective in modifying disease activity or disease progression in adults with idiopathic MPGN.

\section{Cyclophosphamide}

In one study [27], 19 pediatric and adult patients with MPGN were treated with an intensive and prolonged regimen of 
Fig. 3 Electron micrographs show subendothelial deposits with intermesangial interposition in type I MPGN (a) and intramembranous dense deposits in type II MPGN (b). Original magnification: $\mathbf{a} \times 25,000$, b $\times 7000$
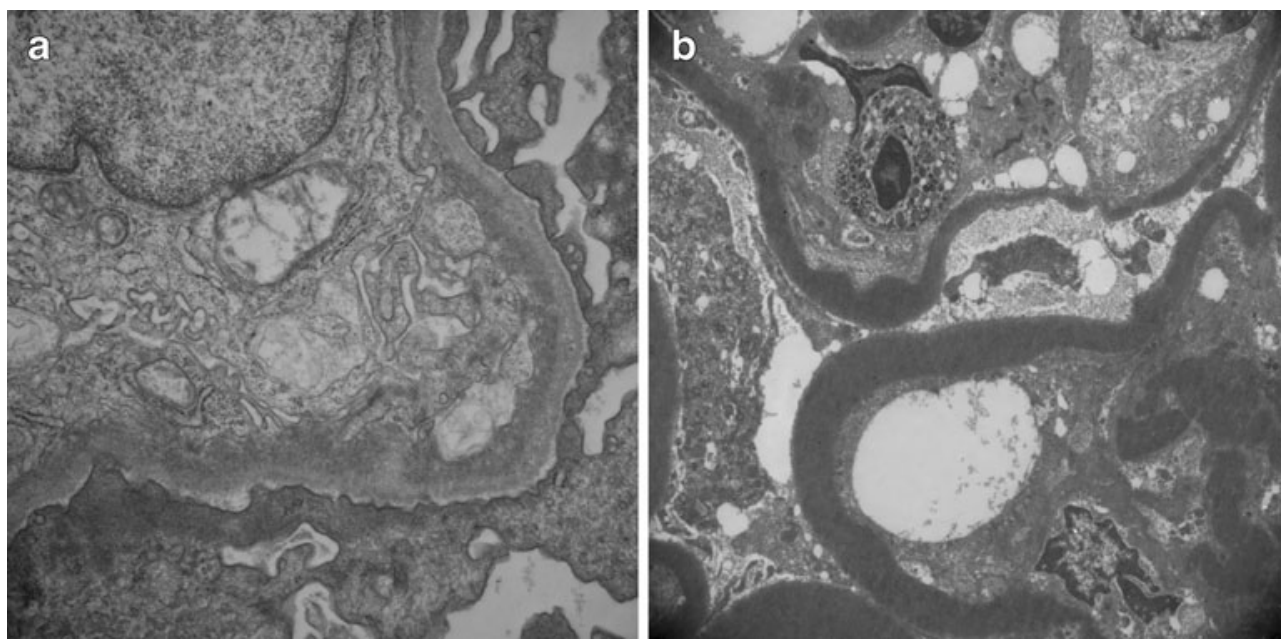

pulse methylprednisolone plus oral prednisone and cyclophosphamide. Of the 19 patients, 15 achieved complete remission and three achieved a partial remission. Based on these results, the researchers concluded that cyclophosphamide is effective in inducing remission and halting the progression of MPGN to ESRD. There are as yet no studies to suggest whether the addition of cyclophosphamide to a prednisolone therapeutic regimen provides any added advantage. Nonetheless, cyclophosphamide is generally recommended in patients with rapidly progressive renal failure or a recent deterioration in renal function, especially those with crescents on histopathology.

\section{Mycophenolate mofetil}

Mycophenolate mofetil (MMF) is an anti-proliferative agent that is being increasingly used for treating patients with various forms of immune-mediated renal disease. In idiopathic MPGN, preliminary studies suggest that the combination of MMF and corticosteroid can, in the short term, reduce proteinuria and may preserve renal function $[28,29]$.

\section{Cyclosporine}

The efficacy of cyclosporine was tested in a recent trial involving 18 patients with refractory MPGN who also received small doses of prednisolone $(0.15 \mathrm{mg} / \mathrm{kg} /$ day $)$. Long-term reductions in proteinuria with preservation of renal function was observed in 17 of the patients, suggesting that cyclosporine can be considered in corticosteroidresistant primary MPGN [30].

\section{Plasma exchange}

Plasma exchange has not been studied in a controlled manner. Success has been reported for the treatment of type
II MPGN recurring after transplantation [13]; however, there are no long-term data on graft survival. There is some evidence that patients with Factor $\mathrm{H}$ deficiency may benefit from plasma exchange [31, 32].

\section{Antiplatelet therapy}

The rationale for antiplatelet therapy is that platelet consumption is increased in MPGN and that platelets may play a role in glomerular injury. The combination of aspirin ( $975 \mathrm{mg} /$ day) and dipyridamole ( $275 \mathrm{mg} /$ day) was found to have useful effects on renal function in a randomized double-blind placebo-controlled trial in 40 patients with idiopathic MPGN, including children [33]. However, these same authors retracted this conclusion in a subsequent study [34]. Another study reported a clinically significant reduction in proteinuria in patients treated with aspirin (500 $\mathrm{mg} /$ day) and dipyridamole $(75 \mathrm{mg} /$ day), but very little change in the GFR [35].

\section{Possible future therapeutic strategies}

Anti-inflammatory agents, such as corticosteroids, may have useful effects in treating MPGN, but their nonspecific nature and adverse effects mean that a high price is paid for any beneficial effect on the renal lesion. More selective forms of anti-inflammatory therapy are becoming available [36], and these are aimed at individual proinflammatory mediators, such as tumor necrosis factor (which can be neutralized with specific antibodies) or interleukin (IL)-1 (the effect of which can be abrogated using soluble IL-1 receptor antagonist). Therapies which inhibit complement activation by both the classical and alternative pathways, such as eculizumab (an anti-C5 antibody designed to decrease C5a-mediated glomerular damage), should also be considered. Another attractive strategy which merits study is to reduce $\mathrm{C} 3 \mathrm{NeF}$ using 


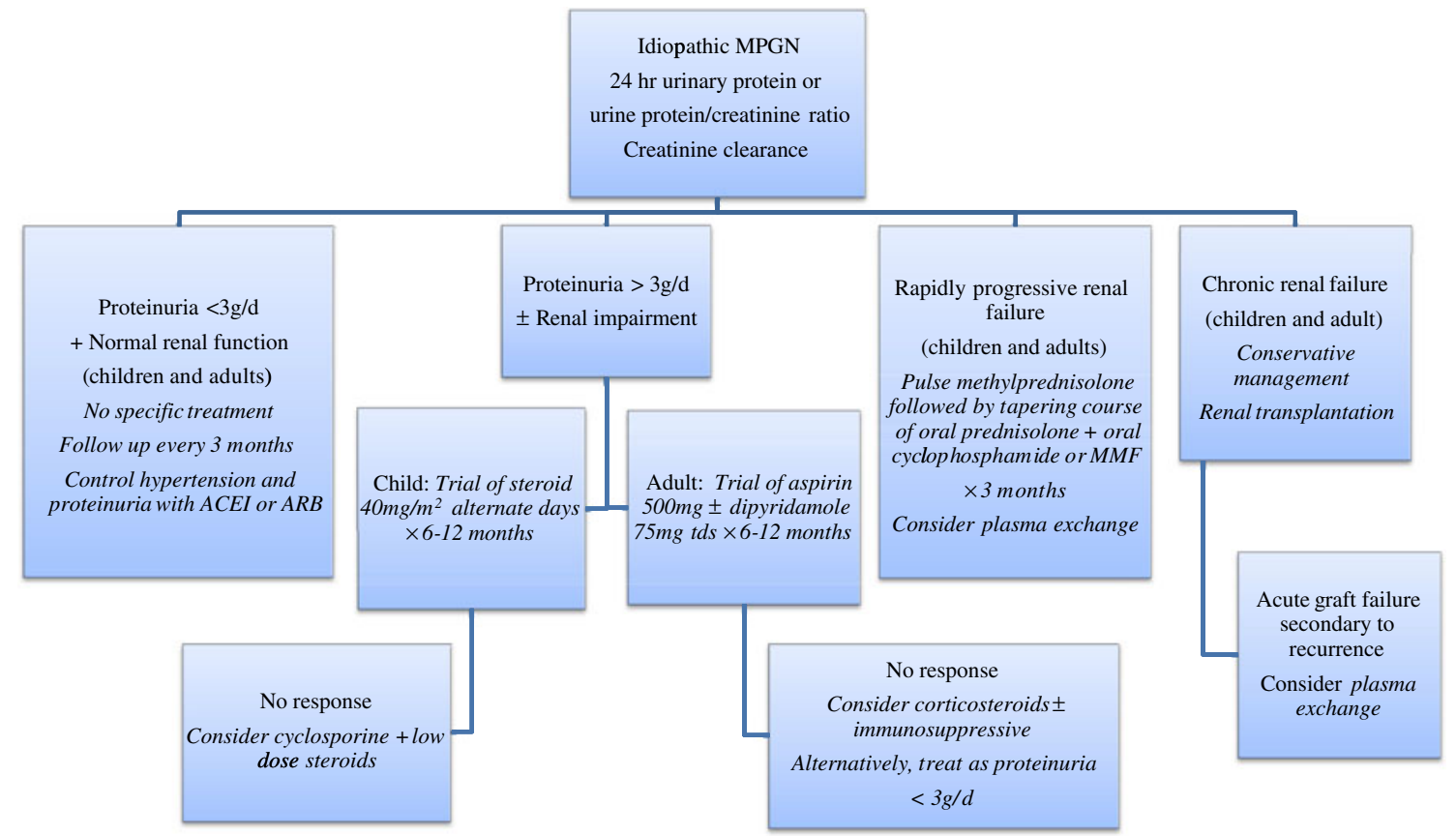

Fig. 4 Treatment options of idiopathic MPGN depending on the level of proteinuria and renal dysfunction. ARB Angiotensin receptor blocking agent, $A C E I$ angiotensin-converting enzyme inhibitor, $M M F$ mycophenolate mofetil

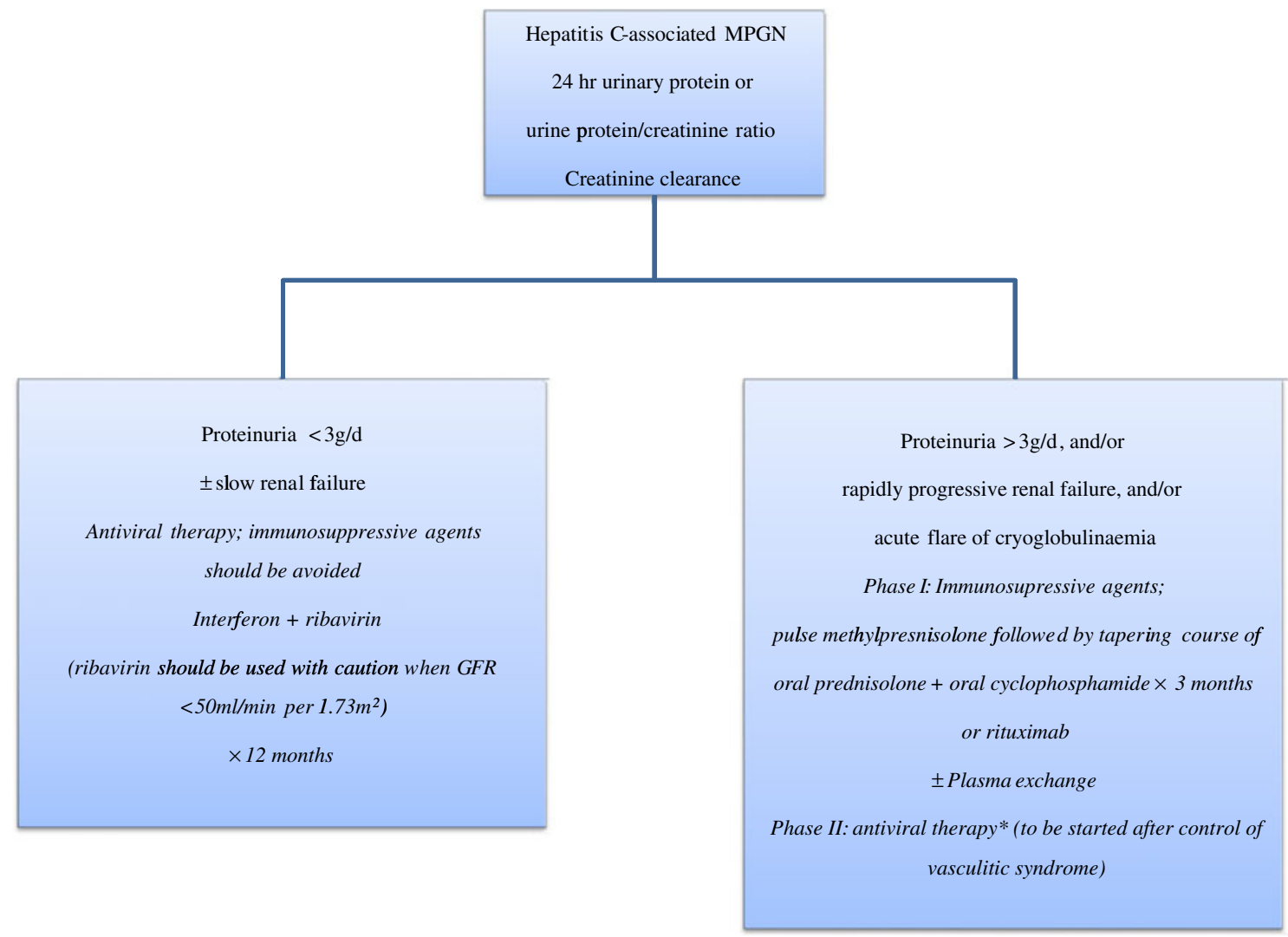

Fig. 5 Management of hepatitis C-associated cryoglobulinemic MPGN. GFR Glomerular filtration rate, * as described in the opposite box under proteinuria $<3 \mathrm{~g} / \mathrm{d}$ 
rituximab (a chimeric IgG1 monoclonal antibody that specifically targets the CD20 surface antigen expressed on B lymphocytes). The improved understanding of the pathogenesis of MPGN is likely to result in the identification of future agents that will modify the intense cellular proliferation and immune deposition seen in this glomerular disease.

In summary, the therapeutic options in idiopathic MPGN depend on the level of proteinuria and kidney failure, as shown in Fig. 4. Management of patients with hepatitis $\mathrm{C}$-associated cryoglobulinemic MPGN is also dictated by the severity of proteinuria and renal dysfunction [37], necessitating two distinct approaches, as shown in Fig. 5. In all patients, the empiric use of angiotensinconverting enzyme inhibitors or angiotensin II receptor antagonists, as drugs of first choice to treat hypertension and decrease proteinuria, is a common practice that may retard the progression of renal disease. Treatment of recurrent MPGN in renal transplant is uncertain, but plasma exchange may be useful in patients whose renal function deteriorates rapidly [13], whereas rituximab seems to be an effective treatment in the presence of cryoglobulinemia [2, 37]. Lastly, improvement in renal outcomes for patients with MPGN largely relies on the evaluation of more selective agents in future studies.

Acknowledgments This work was supported by the NIHR Cambridge Biomedical Research Centre.

\section{Questions:}

(Answers appear following the question list)

1. Which of the following statements regarding the prevalence of MPGN is true?

a) MPGN is more common in Europe and North America

b) MPGN usually affects children and young adults with a male to female ratio of $3: 1$

c) MPGN accounts for approximately $5 \%$ of the primary renal causes of nephrotic syndrome in children and adults

d) MPGN is a common cause of ESRD in children

2. Which of the following statements regarding $\mathrm{C} 3 \mathrm{NeF}$ is correct?

a) $\mathrm{C} 3 \mathrm{NeF}$ is an $\mathrm{IgM}$ autoantibody

b) $\mathrm{C} 3 \mathrm{NeF}$ can be found in healthy subjects

c) $\mathrm{C} 3 \mathrm{NeF}$ prevents the inactivation of $\mathrm{C} 3$ convertase $(\mathrm{C} 3 \mathrm{bBb})$ by factor I

d) $\mathrm{C} 3 \mathrm{NeF}$ is a surrogate marker of disease progression
3. Which of the following histological features is the most characteristic of MPGN?

a) Duplication of the glomerular basement membrane

b) Crescent formation

c) Effacement of the podocyte foot process

d) Positive staining for C4 along the glomerular capillaries

4. Which of the following statements regarding the recurrence of MPGN in kidney transplantation is true?

a) More common in type I MPGN

b) Is usually benign

c) Nephrotic-range proteinuria is a risk factor for recurrence

d) Can morphologically resemble transplant glomerulopathy

5. Which of the following regarding the treatment of idiopathic MPGN is true?

a) The rarity of MPGN makes the randomized controlled study design easy to implement

b) There is a good evidence that the combination of aspirin and dipyridamole slows the progression of the disease

c) Steroid therapy has been proven effective for children but not for adults

d) Cyclosporine is generally recommended in patients with rapidly progressive renal failure

\section{References}

1. Kher V, Gulati S (2005) Mesangiocapillary glomerulonephritis. In: Davidson AM (ed) Oxford textbook of clinical nephrology, 3rd edn. Oxford University Press, Oxford, pp 523-545

2. Alpers CE, Smith KD (2008) Cryoglobulinemia and renal disease. Curr Opin Nephrol Hypertens 17:243-249

3. Orth SR, Ritz E (1998) The nephrotic syndrome. N Engl J Med 338:1202-1211

4. Ozkaya N, Cakar N, Ekim M, Kara N, Akkök N, Yalçinkaya F (2004) Primary nephrotic syndrome during childhood in Turkey. Pediatr Int 46:436-438

5. Asinobi AO, Gbadegesin RA, Adeyemo AA, Akang EE, Arowolo FA, Abiola OA, Osinusi K (1999) The predominance of membranoproliferative glomerulonephritis in childhood nephrotic syndrome in Ibadan, Nigeria. West Afr J Med 18:203-206

6. Warady BA, Hébert D, Sullivan EK, Alexander SR, Tejani A (1997) Renal transplantation, chronic dialysis, and chronic renal insufficiency in children and adolescents. The 1995 annual report of the North American pediatric renal transplant cooperative study. Pediatr Nephrol 11:49-64

7. Kai H, Shimizu Y, Hagiwara M, Yoh K, Hirayama K, Yamagata K, Ohba S, Nagata M, Koyama A (2006) PostMRSA infection glomerulonephritis with marked Staphylococcus aureus cell envelope antigen deposition in glomeruli. J Nephrol 19:215-219

8. Walker PD (2007) Dense deposit disease: new insights. Curr Opin Nephrol Hypertens 16:204-212 
9. Smith KD, Alpers CE (2005) Pathogenic mechanisms in membranoproliferative glomerulonephritis. Curr Opin Nephrol Hypertens 14:396-403

10. Nakopoulou L (2001) Membranoproliferative glomerulonephritis. Nephrol Dial Transplant 16:71-73

11. Berger SP, Daha MR (2007) Complement in glomerular injury. Semin Immunopathol 29:375-384

12. Williams DG (1997) C3 nephritic factor and mesangiocapillary glomerulonephritis. Pediatr Nephrol 11:96-98

13. Appel GB, Cook HT, Hageman G, Jennette JC, Kashgarian M, Kirschfink M, Lambris JD, Lanning L, Lutz HU, Meri S, Rose NR, Salant DJ, Sethi S, Smith RJ, Smoyer W, Tully HF, Tully SP, Walker P, Welsh M, Würzner R, Zipfel PF (2005) Membranoproliferative glomerulonephritis type II (dense deposit disease): an update. J Am Soc Nephrol 16:1392-1403

14. Braun MC, Strife CF (2004) Membranoproliferative glomerulonephritis. In: Kaplan BS, Meyers KEC (eds) Pediatric nephrology and urology: the requisites in pediatrics. Elsevier, Philadelphia, pp $147-155$

15. West CD, McAdams AJ (1998) Membranoproliferative glomerulonephritis type III: association of glomerular deposits with circulating nephritic factor-stabilized convertase. Am J Kidney Dis $32: 56-63$

16. Cameron JS, Turner DR, Heaton J, Williams DG, Ogg CS, Chantler C, Haycock GB, Hicks J (1983) Idiopathic mesangiocapillary glomerulonephritis. Comparison of types I and II in children and adults and long-term prognosis. Am J Med 74:175-192

17. Varade WS, Forristal J, West CD (1990) Patterns of complement activation in idiopathic membranoproliferative glomerulonephritis, types I, II, and III. Am J Kidney Dis 16:196-206

18. Cansick JC, Lennon R, Cummins CL, Howie AJ, McGraw ME, Saleem MA, Tizard EJ, Hulton SA, Milford DV, Taylor CM (2004) Prognosis, treatment and outcome of childhood mesangiocapillary (membranoproliferative) glomerulonephritis. Nephrol Dial Transplant 19:2769-2777

19. Braun MC, Stablein DM, Hamiwka LA, Bell L, Bartosh SM, Strife CF (2005) Recurrence of membranoproliferative glomerulonephritis type II in renal allografts: the North American pediatric renal transplant cooperative study experience. J Am Soc Nephrol $16: 2225-2233$

20. Rennke HG (1995) Secondary membranoproliferative glomerulonephritis. Kidney Int 47:643-656

21. Silva FG (1998) Membranoproliferative glomerulonephritis. In: Heptinstall RH (ed) Pathology of the kidney. Lippincott-Raven, Philadelphia, pp 309-368

22. Fogo AB, Kashgarian M (2005) Membranoproliferative glomerulonephritis. In: Diagnostic atlas of renal pathology. Elsevier Saunders, Madrid, pp 64-84

23. Burkholder PM, Marchand A, Krueger RP (1970) Mixed membranous and proliferative glomerulonephritis. A correlative light, immunofluorescence, and electron microscopic study. Lab Invest 23:459-479

24. Levin A (1999) Management of membranoproliferative glomerulonephritis: evidence-based recommendations. Kidney Int 70:S41-S46

25. Tarshish P, Bernstein J, Tobin JN, Edelmann CM Jr (1992) Treatment of mesangiocapillary glomerulonephritis with alternate-day prednisone - a report of the International Study of Kidney Disease in Children. Pediatr Nephrol 6:123-130
26. Somers M, Kertesz S, Rosen S, Herrin J, Colvin R, Palacios de Carreta N, Kim M (1995) Non-nephrotic children with membranoproliferative glomerulonephritis: are steroids indicated? Pediatr Nephrol 9:140-144

27. Faedda R, Satta A, Tanda F, Pirisi M, Bartoli E (1994) Immunosuppressive treatment of membranoproliferative glomerulonephritis. Nephron 67:59-65

28. De S, Al-Nabhani D, Thorner P, Cattran D, Piscione TD, Licht C (2009) Remission of resistant MPGN type I with mycophenolate mofetil and steroids. Pediatr Nephrol 24:597-600

29. Jones G, Juszczak M, Kingdon E, Harber M, Sweny P, Burns A (2004) Treatment of idiopathic membranoproliferative glomerulonephritis with mycophenolate mofetil and steroids. Nephrol Dial Transplant 19:3160-3164

30. Bagheri N, Nemati E, Rahbar K, Nobakht A, Einollahi B, Taheri S (2008) Cyclosporine in the treatment of membranoproliferative glomerulonephritis. Arch Iran Med 11:26-29

31. Licht C, Heinen S, Józsi M, Löschmann I, Saunders RE, Perkins SJ, Waldherr R, Skerka C, Kirschfink M, Hoppe B, Zipfel PF (2006) Deletion of Lys224 in regulatory domain 4 of Factor $\mathrm{H}$ reveals a novel pathomechanism for dense deposit disease (MPGN II). Kidney Int 70:42-50

32. Jansen JH, Høgåsen K, Harboe M, Hovig T (1998) In situ complement activation in porcine membranoproliferative glomerulonephritis type II. Kidney Int 53:331-349

33. Donadio JV Jr, Anderson CF, Mitchell JC 3rd, Holley KE, Ilstrup DM, Fuster V, Chesebro JH (1984) Membranoproliferative glomerulonephritis. A prospective clinical trial of plateletinhibitor therapy. N Engl J Med 310:1421-1426

34. Donadio JV Jr, Offord KP (1989) Reassessment of treatment results in membranoproliferative glomerulonephritis, with emphasis on lifetable analysis. Am J Kidney Dis 14:445-451

35. Zäuner I, Böhler J, Braun N, Grupp C, Heering P, Schollmeyer $P$ (1994) Effect of aspirin and dipyridamole on proteinuria in idiopathic membranoproliferative glomerulonephritis: a multicentre prospective clinical trial. Collaborative Glomerulonephritis Therapy Study Group (CGTS). Nephrol Dial Transplant 9:619-622

36. Smith RJ, Alexander J, Barlow PN, Botto M, Cassavant TL, Cook HT, de Córdoba SR, Hageman GS, Jokiranta TS, Kimberling WJ, Lambris JD, Lanning LD, Levidiotis V, Licht C, Lutz HU, Meri S, Pickering MC, Quigg RJ, Rops AL, Salant DJ, Sethi S, Thurman JM, Tully HF, Tully SP, van der Vlag J, Walker PD, Würzner R, Zipfel PF (2007) Dense deposit disease focus group, new approaches to the treatment of dense deposit disease. J Am Soc Nephrol 18:2447-2456

37. Fabrizi F, Lunghi G, Messa P, Martin P (2008) Therapy of hepatitis C virus-associated glomerulonephritis: current approaches. J Nephrol $21: 813-825$

\section{Answers:}

1) $\mathrm{C}$

2) $\mathrm{B}$

3) A

4) D

5) $\mathrm{C}$ 